\title{
Designing new lubricant additives using biomimetics
}

\author{
A. Morina, T. Liskiewicz \& A. Neville \\ Corrosion and Surface Engineering Research Group, \\ School of Mechanical Engineering, University of Leeds, Leeds, UK
}

\begin{abstract}
Nature produces some complex nanocomposite structures having the following properties, self-healing capability, functional gradation and smartness. These properties are all required of tribofilms in the field of lubrication technology where their structure, formation and removal rate and smartness are key to their ability to maintain fuel economy and durability. In this paper the potential for using biomimetic principles in the field of tribology and specifically as a means of improving tribological performance in the boundary lubrication regime is investigated. The paper initially describes the challenges associated with operating tribological contacts in the boundary lubrication regime, assesses the need for new approaches to lubrication and gives a preliminary appraisal of biomimetic principles applied to this engineering problem.

Keywords: biomimetics, tribology, tribofilm, TRIZ, bionanocomposites.
\end{abstract}

\section{Introduction}

\subsection{Setting the scene - current situation in lubricant additive technology}

It is perhaps surprising that a link can be made between claims from ecologists, (reported in the national press [1]) that 1,000,000 species could be extinct in the next decade and engine lubrication. However, passenger and commercial light vehicles have been estimated [2] to account for $20 \%$ of the total $\mathrm{CO}_{2}$ delivered into the atmosphere from hydrocarbon sources in the US and other developed countries. When the population of vehicles in the western world is considered, it is perhaps easier to see how a realistic link between tribology and ecology can be made. According to recent UK government statistics [3], in 2000 in the UK alone 
there were 29 million motor vehicles registered for use on the public highway. International numbers are even more impressive, with the total number of road vehicles in service in Europe, Japan and the USA in 1999 being of the order of 530 million. Bearing in mind that this total excludes all of Asia except Japan, former Soviet block countries, Australasia, Africa and South America then the staggering scale of the use of the reciprocating internal combustion engine becomes clear.

On a global scale there is a real urgency to achieve step changes in the level of $\mathrm{CO}_{2}$ emission. Reduction of $\mathrm{CO}_{2}$ emissions is achieved by increasing fuel economy and, as summarised by Okuno and Bessho [4] there are several means of achieving "good gas mileage" (Figure 1). Advances are being made in both areas 1 and 2 as defined in Figure 1. With respect to 2, weight reduction and reduced aerodynamic resistance [5] have been instrumental in achieving the $30 \%$ reduction in fuel consumption of the new Volkswagen Lupo 3L TDI. As material development continues at an alarming rate and evermore new alloys [6], composites and nano-engineered structures are developed and embraced by the automotive sector [7], it is expected that the trend will continue.

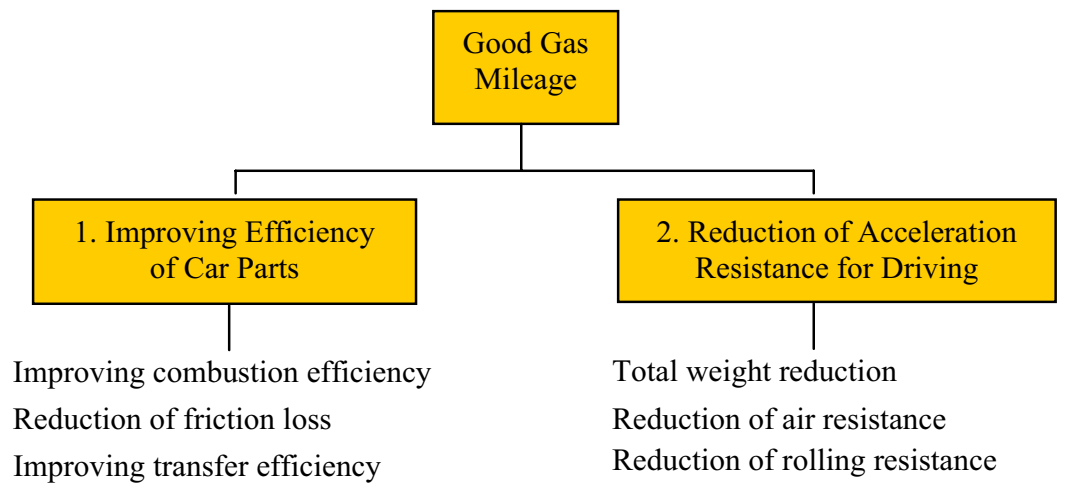

Figure 1: Techniques for improving fuel economy [4].

However, by far the greatest challenges for engineers in terms of maintaining engine performance are associated with area 1 and, in particular, with components operating in the boundary lubrication regime. It is in this regime that metal-to-metal asperity contact occurs and high friction and wear rates ensue if proper protection, in the form of lubricant additives, is not used.

Understanding the nature of the additives used in formulated engine oils to reduce wear, lower friction, maintain engine cleanliness and reduce soot formation has been the subject of much research since the advent of commercial lubricant additives in the early 1940s. Dominating in this respect has been the anti-wear additive Zinc DialkylDithioPhosphate (ZDDP).

It is critical to understand a few aspects of tribology in the boundary lubrication regime if the challenge of replacing boundary lubricant additives is fully appreciated. The performance of the contact in terms of friction and wear 
are dependent on the formation of a tribofilm. The tribofilm is a very thin layer (in the order of tens of nanometres) which covers the asperities and prevents direct metal/metal contact. Work to characterise the tribofilm has been successful in terms of being able to understand its structure, chemical composition and mechanical properties. One example of a schematic representation of the tribofilm is presented in Figure 2.

Of key importance to this proposal are the following aspects of the tribofilm

- It spontaneously forms through intimate contact/interaction between the surface and the lubricant additives

- It has a layered structure on a nanometric scale comprising a base glassy structure and an upper organic-rich layer.

- It is self-healing

- It is smart - it reacts to changes in load, temperature, pressure, sliding speed

All in all the tribofilm is an example of the ultimate smart, nanocomposite material.

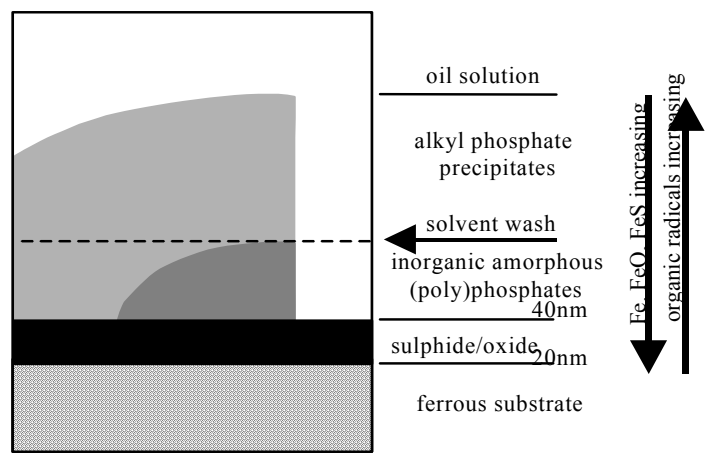

Figure 2: $\quad$ Schematic representation of tribofilm layered structure [8].

The fact that the film has all these amazing attributes is by accident rather than any so called molecular engineering when the lubricant additive was first derived. There is no literature to account for the development of the ZDDP antiwear additives which have been the workhorse for lubricant technology for over 60 years.

Now that radical changes in lubricant additive technology are being forced on formulators, primarily through changes in legislation, there is a need for a more radical, innovative and risky approach to new additive design. Incremental steps are being made to get towards environmentally-acceptable solutions to achieve target $\mathrm{CO}_{2}$ emissions, alongside retained engine performance but these are unlikely to deliver any more than an incremental move to keep in line with the shifting targets imposed by government. As examples:

- The level of P has progressively decreased from $0.12 \mathrm{wt} \%$ in 1993 for ILSAC (International Lubricant Standardization and Approval 
Committee) GF-1 oils, to $0.1 \mathrm{wt} \%$ in 1996 and 2001 (GF-2 \& 3) and it will be further reduced to $0.08 \mathrm{wt} \%$ when GF-4 is introduced.

- The CHON concept (lubricating engines with only Carbon, Hydrogen, Oxygen and Nitrogen) has been introduced by formulators although no real progress in this respect has been made

- Alternative additives, some based on e.g B, are being introduced to replace some of the functionality of $\mathrm{P}$. Future legislation on Bcontaining compounds is not yet clear

To use biomimicry to develop a new generation of lubricant additives challenges conventional thinking with respect to additive design.

Table 1: $\quad$ Rationale for choosing the biomimetic approach.

\begin{tabular}{|c|c|}
\hline $\begin{array}{c}\text { Natural Materials/Biological } \\
\text { Systems }\end{array}$ & Tribology/Tribofilm Analogies \\
\hline $\begin{array}{l}\text { Nature provides us with infinite } \\
\text { examples of where reactions } \\
\text { spontaneously occur as a result of } \\
\text { surface/environment interactions }\end{array}$ & $\begin{array}{l}\text { Tribofilm formation is critically } \\
\text { controlled by the nature of } \\
\text { surface/environment interactions }\end{array}$ \\
\hline $\begin{array}{l}\text { Numerous } \\
\text { composites (or O-I hybrids) are seen } \\
\text { in nature (e.g. proteins and } \\
\text { polysaccharides with calcium } \\
\text { carbonate produced at a cellular level; } \\
\text { molluscs [12]; coccolithophores [13]) }\end{array}$ & $\begin{array}{l}\text { Their structures can be viewed as } \\
\text { potential tribofilm materials since } \\
\text { the key component of a tribofilm is } \\
\text { the blend of inorganic glass/organic } \\
\text { material }\end{array}$ \\
\hline $\begin{array}{l}\text { Biocomposites often have complex } \\
\text { layered structures with functional } \\
\text { gradation (Figure } 3 \text { ). Their structure is } \\
\text { controlled by constituents of the } \\
\text { surrounding fluid (e.g proteins } \\
\text { (silaffins) controlling silica structure } \\
\text { growth) }\end{array}$ & $\begin{array}{l}\text { The successful formation of } \\
\text { tribofilms depends on the ability of } \\
\text { layers with low shear strength and } \\
\text { layers with high strength and } \\
\text { toughness to co-exist in a complex } \\
\text { arrangement. Their structure } \\
\text { depends on the constituents in the } \\
\text { lubricant and their surface } \\
\text { reactivity. }\end{array}$ \\
\hline $\begin{array}{l}\text { In biomineralisation the biomolecules } \\
\text { catalyse and direct the synthesis of } \\
\text { organic networks to produce hybrid } \\
\text { structures (often with stunning } \\
\text { complexity) }\end{array}$ & $\begin{array}{l}\text { In tribofilm formation one key } \\
\text { aspect is the replenishment of } \\
\text { reactants at the surface to } \\
\text { continually re-form and repair the } \\
\text { film }\end{array}$ \\
\hline $\begin{array}{l}\text { Natural structures (e.g plants) can } \\
\text { adapt in real time to their } \\
\text { environment. They sense the data, } \\
\text { process the data and respond. }\end{array}$ & $\begin{array}{l}\text { For tribofilms to be fully effective } \\
\text { they must be able to react to their } \\
\text { environment - they must sense for } \\
\text { example cold start conditions, } \\
\text { production of wear debris, changing } \\
\text { lubrication regime }\end{array}$ \\
\hline $\begin{array}{l}\text { Nature presents renewable structures } \\
\text { from inorganic and organic structures } \\
\text { (e.g ormosils) [14] }\end{array}$ & $\begin{array}{l}\text { Tribofilms must be renewable from } \\
\text { sources within the lubricating fluid. } \\
\text { Formation and replenishment rates } \\
\text { are key to sustainability. }\end{array}$ \\
\hline
\end{tabular}




\section{Synthesising natural bionanocomposites}

\subsection{Rationale for using nature as lead}

There are many examples of the successful use of biomimicry for the derivation of new structural materials such as ceramics with improved toughness based on mother of pearl [9], underwater adhesives based on mussel adhesives [10] and adhesive tape based on the Gecko foot mechanism [11].

However, no applications in boundary lubrication tribology exist. A clear distinction between this approach and the vast work on biotribology must be made. In biotribology, the tribological performance of biological systems is evaluated. In this current paper the focus is entirely different; the aim being to assess the feasibility of using complex biocomposites as a basis for synthetic derivatives for real engineering tribological systems. These demand stability at high temperature, high pressures, high shear rates - not at all the same requirements for biotribology systems.

Biocomposites are proposed as the route towards achieving this step change in lubricant technology rather than nanocomposites per se due to their inherent potential for greenness - a feature of major importance for tomorrow's lubricants.

So why is there even a glimmer of hope that new generation lubricant additives can be derived using this approach? In Table 1 the analogies between tribofilm characteristics (i.e. requirements) and natural biomaterials are given which provide an indication of some potential areas for progress to be made.

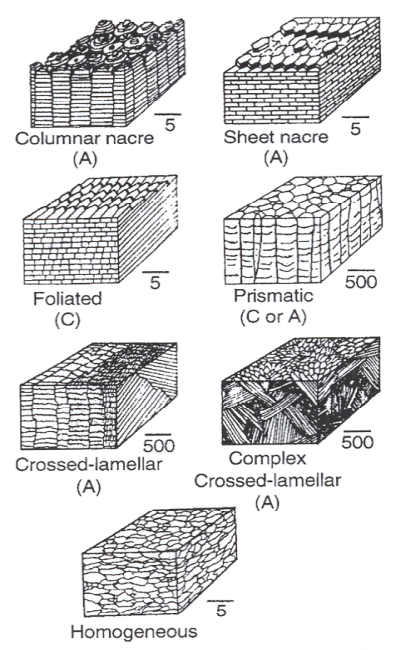

(a)

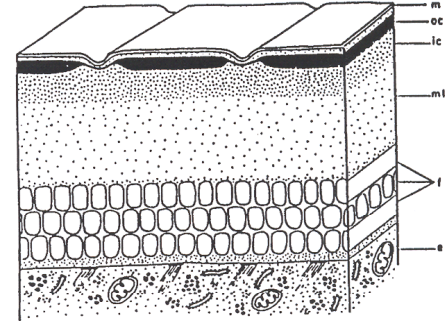

(b)

Figure 3: $\quad$ (a) Types of mollusc shell material [15]. Illustrating the complexity of the composite structures (b) Outer covering of roundworm skin nanocomposite properties and functional gradation are evident [16]. 


\subsection{Identifying bio-systems with potential for mimicry in lubrication systems}

The strategy applied to accomplish the aim of this work, which can be summarised as, "to solve lubrication problems through synthesising naturalderived bionanocomposites", involves work in two directions:

1. Identification of natural systems where there is a lubrication process and study the mechanism of lubrication. This involves conducting casestudies which will result in selecting natural material systems to be used as models for synthetic efforts.

2. Identification of the mechanisms used in nature for providing selfhealing structures and "smart" materials and study the possibilities to mimic the mechanisms used to form them and not completely the structure. This involves the use of a molecular biomimetics concept [17] to bridge the materials-biology gap. Using this concept, hybrid materials that would replace current tribofilms could be potentially assembled from the molecular level.

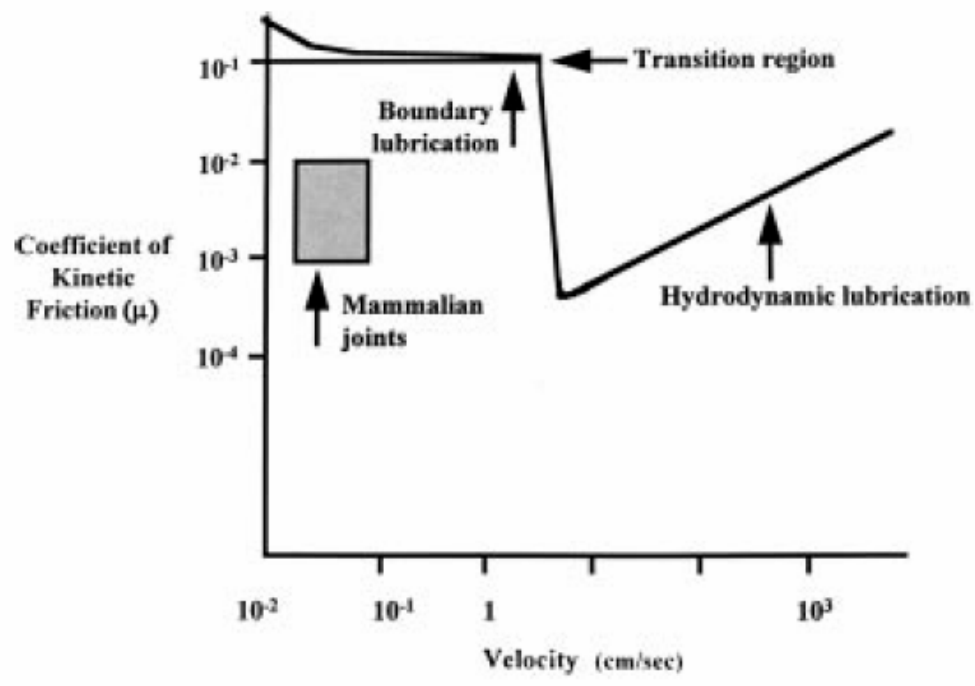

Figure 4: Mammalian joints friction in Stribeck curve.

These two directions are interconnected since most lubricated systems in nature use materials with unique properties.

The most obvious example is the lubrication in mammalian joints. Figure 4 shows the relation of the friction coefficient in these joints with the friction values obtained by existing technology in a Stribeck curve [18]. This demonstrates how either hydrodynamic lubrication needs to be extended to velocities two orders of magnitude lower or the natural boundary lubricants are superior to their synthetic counterparts by much the same margin [18]. The low 
friction in these joints shows the remarkable solution provided by nature. Analysing the lubrication characteristics of this very effective lubricated system in nature, it can be seen that materials lubricated and the lubricant are considered as a single system (interaction of articular cartilage with synovial fluid).

There is still a great debate about the definite mechanism of lubrication in joints [19] but whichever mechanism is applied it can be of great importance to lubrication of engineered materials. Nature has solved the friction problem in mammalian joints by either maintaining a hydrodynamic lubrication through using a special material (articular cartilage) or/and producing a very effective boundary film on the surface of the articular cartilage. Industry has begun to appreciate that efficient lubrication of engine components cannot be achieved solely by improving the lubricants and their chemical composition but a "system solution", involving both the surface to be lubricated and the lubricant should be applied [20], a concept which is applied in nature.

\section{TRIZ - helping to solve the problem?}

Designing new lubricant additives using biomimetics principles represents a challenging problem and progress towards solving this problem requires a structured way of thinking and transferring ideas between biology and engineering [21]. To support this the original problem solving methodology TRIZ (Teoriya Resheniya Izobreatatelskikh Zadach), which is a Soviet initiated Theory of Inventive Problem Solving [22] is being used. TRIZ is a mixture of philosophy, methodology and specific tools which all together make the research process significantly quicker, more effective but mainly much more innovative than traditional Western methods, like brain storming or lateral thinking. The power of TRIZ comes from a key finding that all of the world's most outstanding solutions emerge from a repeatable, very small number of inventive principles. These have been identified using the knowledge and experience of former inventors through a study of more than 3 million successful patents to date.

\subsection{Problem definition}

TRIZ provides a number of tools not only to solve, but initially to properly define, a problem. The definition stage is crucial for successful output of each project and is usually harder and longer to complete than the second, solution stage. From the choice of different problem definition tools offered by TRIZ, such as Problem Explorer, Function/Attribute Analysis, S-Curves and Ideal Final Result, the S-Curves methodology has been adopted in this project in order to identify how mature the current lubrication technology system is (Figure 5(a)). The S-Curve depicts the level of ideality of a system as a function of time. Generally ideality is defined as the benefits divided by a sum of cost and harm. In our case the benefits are related to low friction and low wear, cost factor to lubrication expense and harm factor to environmental issues. TRIZ recommends that the S-Curve is analysed in order to determine how ideal the current system is and, as a result, to decide if there is potential for further development or whether a novel (and often radical) approach is required. 
The analysis of current lubrication technology suggests that for a number of reasons the current system is in the retirement phase. The conception of lubrication can be dated back to Ancient Egypt civilisation when some olive oil was poured under the runners of great sledges dragged along by sleeves to reduce friction. Nevertheless, the birth of real lubrication technology coincides with the technical revolution at the beginning of the twentieth century. The sudden growth of main classes of lubricant additives took place in the 1930s and 1940s when the need for well-lubricated and reliable machines increased rapidly, partly due to wartime demands (Figure 5(b)). From the 1950 s until now lubrication technology has constantly been developed. Significant progress towards optimising current additive technology has been made in parallel with chemical characterisation tools evolving. "Design" of additives was made possible once key functionality of additives was delivered. Molecular modelling introduced into this area in the last 10 years has added to the capabilities of synthetic chemists in being able to design and make functional additives. There is little doubt that the speed at which lubricant additive technology is evolving has slowed in the last decade - partly due to the ever-increasingly stringent legislative constraints imposed on additive manufacturers. Taking into account that official legislations force further reduction of phosphorus and sulphur, the ideality of a lubrication technology is likely to drop from the current level as the removal of those compounds will dramatically decrease the benefits unless effective replacements are found.

(a)

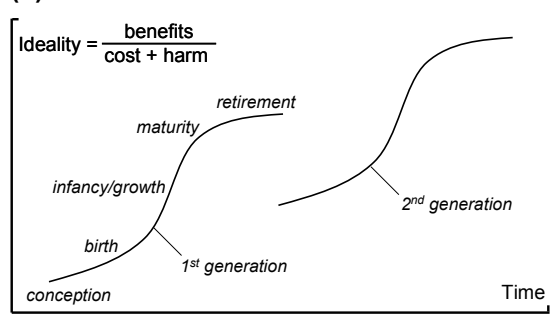

(b)

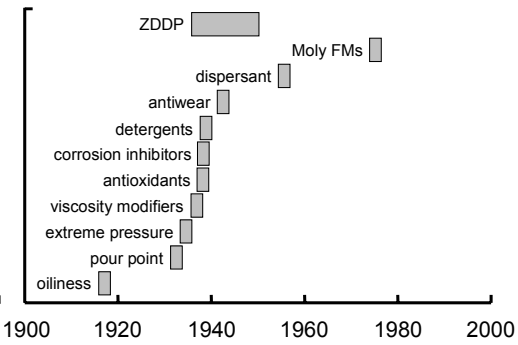

Figure 5: (a) S-Curve characteristics; (b) chronology of development of main classes of lubricant additive [23].

Summarising the S-Curve analysis for a current lubrication technology, there is little scope for the development of a present system and so the most likely way to improve the ideality is through introduction of a new approach. The next generation technology will be characterised by another S-Curve and the initial ideality is likely to be even lower than that for a current system. Nevertheless, it will be on the first - concept stage, from which the ideality will evolve with time according to the S-Curve shape to yield longer term benefits.

\subsection{Problem solution methodology}

Finding the problem solution using the TRIZ methodology is the next stage of the project. Generally to benefit from rich TRIZ opportunities, the specific 
problem needs to be reformulated into an abstract domain (Figure 6), where all TRIZ problem solution tools can be applied: Technical and Physical Contradictions, S-Field Analysis, Laws of Technical Evolution, Resource Identification, Algorithm for Problem Solving, Trimming and Subversion Analysis. To define the desirable specific solution the general solution provided by TRIZ has to be interpreted in the light of an examined problem. The way between Problem and Solution through the TRIZ process in Figure 6 seems to be longer than the direct one, however in practice it has been found to be much quicker and efficient [22], it also generates novel ideas which have not previously been identified.

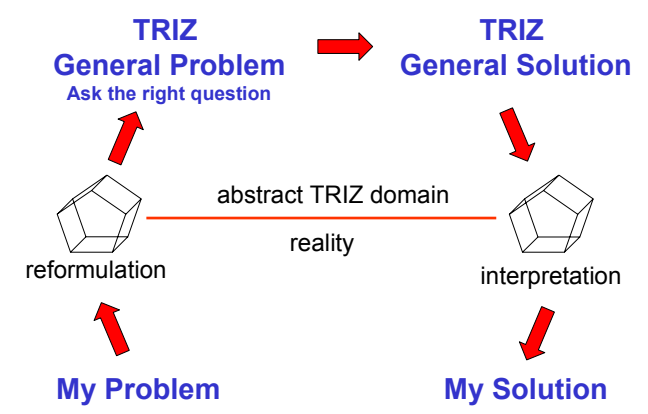

Figure 6: General problem solution path defined by TRIZ researchers.

\section{Remaining challenges and future look}

The application of biomimetic principles in tribology is new and poses some great challenges to engineers and scientists. This preliminary study has identified that there is potential to learn from nature in the area of bionanocomposites thus opening the door to find solutions to lubrication in engineering from nature. There is however some way to go before current additive technology is replaced. To assist in the transfer of ideas between nature and technology, TRIZ has clearly enabled the problem to be defined. The next stage is to use TRIZ to help in the problem solution.

\section{References}

[1] The Independent: Revealed: how global warming will cause extinction of a million species. January 8th 2004.

[2] http://www.ems.org/energy policy/cafe.html.

[3] DTLR (Department of Transport LGatR, Transport Statistics Great Britain 2001, The Stationery Office, London, 2001.

[4] Ukuno K, Bessho T: Need for environmentally friendly surface modification technology in the Japanese automotive industry. Surface Modification Technologies XIV, Ed T S Sudershan and M Jeandin, ASM International:135-140, 2001

[5] Curro S: Economical and earth-friendly, the Lupo 3L TDI, AL Alluminio E Leghe.119-121, 2000 
[6] Powell R: The USAMP Magnesium powertrain cast components project. JOM:49-51, 2002

[7] Presting H, Konig U: Future nanotechnology developments for automotive applications. Materials Science and Engineering, C 23:737741,2003

[8] Bec S, Tonck A, Georges JM, Coy RC, Bell JC, Roper GW: Relationship between mechanical properties and structures of zinc dithiophosphate antiwear films. Proc R Soc Lond A, 455:4181-4203, 1999

[9] Jackson AP, Vincent JFV, Turner RM: A physical model of nacre. Composites Science and Technology, 36:255-266, 1989

[10] Holl SM, Hansen D, Waite JH, Schaefer J: Solid-state NMR analysis of cross-linking in mussel protein glue. Arch Biochem Biophys, 302:255-258, 1993

[11] Geim AK, Dubonos SV, Grigorieva IV, Novoselov KS, Zhukov AA, Shapoval SY: Microfabricated adhesive mimicking gecko foot-hair. Nature Materials, 2:461-463, 2003

[12] Aizenberg J, Lambert G, Addadi L, Weiner S: Adv Materials, 8:222, 1996

[13] R. N. Pienaar in A Winter WGSC, Cambridge University Press, New York, p13, 1994

[14] Castelvetro V, Vita CD: Nanostructured hybrid materials from aqueous polymer dispersions. Advances in Colloid and Interface Science, 108109:167-185, 2004

[15] J. F. V. Vincent, Ceramics from invertebrate animals, in Handbook of Elastic Properties of Solids, Liquids and Gases, edited by Levy, Bass and Stern, Volume III: Elastic Properties of Solids: Biological and Organic materials, Earth and Marine Sciences, 2001.

[16] Vincent JFV, Jeronimidis G, Topping BHV, Khan AI: The mechanical design of skin - towards the development of new materials. 1991.

[17] Sarikaya M, Tamerler C, Alex K -YJ, Schulten K, Baneyx F: Molecular biomimetics: nanotechnology through biology. Nature Materials, 2:577585,2003

[18] Hills BA: Boundary lubrication in vivo. Proc Instn Engrs Part H, 214:8394, 2000

[19] Furey JM: Joint lubrication. In: The biomedical engineering handbook. Edited by Bronzino JD: CRC Press LLC; 2000.

[20] Erdemir A: Review of engineered tribological interfaces for improved boundary lubrication. Tribology International, 38(3):249-256, 2005

[21] Vincent JFV, Mann DL: Systematic technology transfer from biology to engineering. Phil TransRSocLondA, 360:159-173, 2002

[22] Altshuller G: Creativity as an exact science. New York: Gordon \& Breach; 1984.

[23] Spikes H: The history and mechanisms of ZDDP. Tribology Letters, 17(3):469-489, 2004 